\title{
Research and Practice on the IT Outstanding Engineers Education Training Plan based on University-Enterprise Cooperation Alliance
}

\author{
Wenzhun Huang ${ }^{1, a^{*}}$, Xinxin Xie ${ }^{1, b}$ \\ ${ }^{1}$ Department of Electronic Information Engineering, Xijing University, Xi'an, 710123, China \\ aemail: huangwenzhun@xijing.edu.cn, bemail: 346148500@qq.com
}

Keywords: IT; Outstanding Engineers; Education Training; Cooperation Alliance Policy.

\begin{abstract}
In this paper, we conduct research on the IT outstanding engineer education training plan based on university-enterprise cooperation alliance. On basis of field investigation and questionnaire research from the enterprise point of view to understand the status of the cooperation between the colleges and enterprises is analyzed in the form of the university-enterprise cooperation, path and dynamic factors. In the analysis of main factors affecting effect of university-enterprise cooperation on the basis of using backward stepwise regression analysis, extract the key factors influencing the effect of university-enterprise cooperation to promote university-enterprise cooperation effect and promote enterprise technology innovation to provide better service strategy and way. Our research opens up the new perspective of the university-enterprise cooperation pattern which is meaningful.
\end{abstract}

\section{Introduction}

Engineering undergraduate fundamental purpose of higher education reform is to constantly improve the quality of education, cultivate meet the requirements of the times development high quality talents with innovative consciousness, this mainly by institutions of higher learning in the teaching work and work constantly on the steps of engineering teaching reform is teaching and the level of main engine. It can, therefore, universities should develop to meet the needs of the era of high quality talents with innovative consciousness and must constantly deepen the teaching reform to promote the university teaching to improve the teaching quality of the college education. Engineering undergraduate colleges and universities must assess the situation, combined with their own advantages and actively take the various effective measures. The further teaching reform to promote deep levels, this is not only the direction of Chinese higher education reform in the new century but also the inevitable trend of higher education reform. Engineering practice ability evaluation content includes the two aspects of ability evaluation and quality evaluation and the evaluation test of the professional knowledge and practical hands-on ability and innovation ability of professional skills and the ability to approach [1-2].

To numerically analyze the factors, we summarize the measurement aspects into following parts. (1) Engineering design ability. Engineering design is the combination of engineering and graduation design and students play subjective initiative, the application of theoretical knowledge and practical skills to design, creatively presented in the form of graduation design, show the students engineering design ability strong or weak, also reflected the skills to solve the problem of the engineering practice. (2) Problem solving skills. Routine is to solve problem and significance of the purpose of practice and is also the basis for solving the problems. Therefore, problem solving skills as a complete engineering practice tool which is an important part of engineering practice ability. Engineering science and the technology talents as the main force to promote the development of society is solid theory foundation, the conversion for knowledge and use is to build means and methods of engineering practice ability. (3) Practical innovation ability. Innovation comes from the innovation. Innovation is the dare to break through, dare to challenge has mind of knowledge and technology. Have innovation spirit is behavior, to the formation of innovation ability. School is one of the main raining students' innovative ability. The key value is the ability of engineering talent, but also the core elements of engineering practice ability. (4) Ability to operate. A college talent training characteristics is gradually formed in the core 
process of the school in the long-term of running a school in the aspect of talent cultivation of unique and superior to other colleges and the excellent characteristics of recognized by society, it is a major indication of university personnel training quality. Talent training characteristics has characteristics such as the particularity, finiteness, stability and expansibility, any talent cultivation characteristics of colleges and universities only on certain aspects of the talent training or talent cultivation process advantage is formed on a number of links [3].

Private colleges arises at the historic moment, reflects the universal desire for education including on-the-job personnel thirst for knowledge and the parents to their children eager for. To improve their own quality is everyone improve themselves psychological needs and desire. Foreign universities run by the university to give us a lot of inspiration, learning opening University's educational philosophy. Distribution in the system, on the basis of learning theory knowledge and combined with the social practice. Change subject closed advocacy with the general application of the multidisciplinary joint development education. The figure one demonstrates the idea [4].

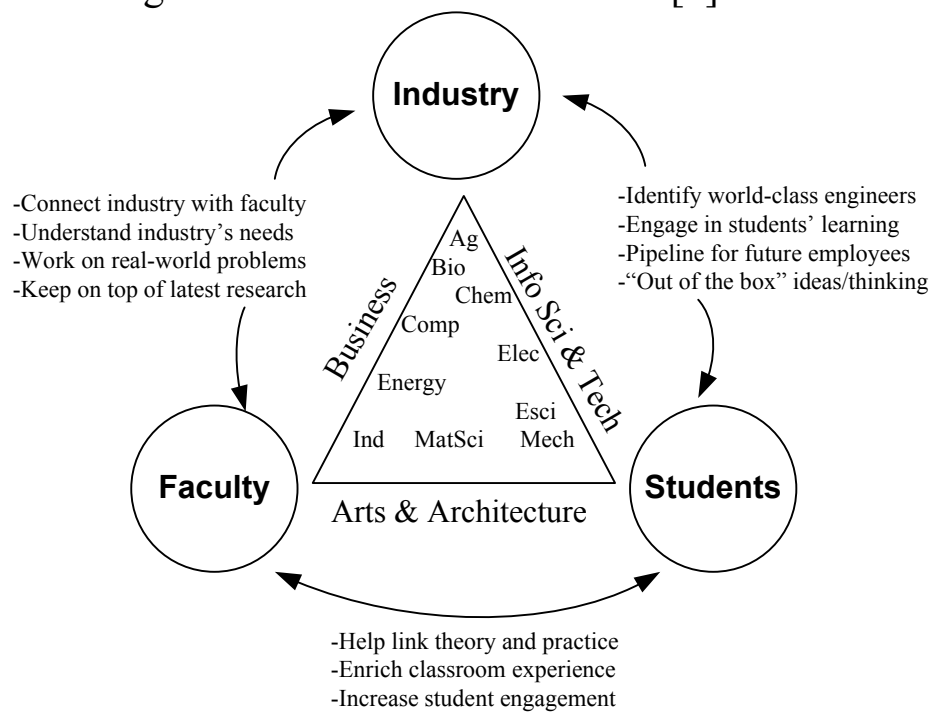

Figure 1. The Opening University Education for the Foreign Agencies

In this paper, we conduct research on the IT outstanding engineer education training plan based on university-enterprise cooperation alliance. The paper is organized as the follows. In the first section, we demonstrate the principles and primary concepts of the university-enterprise cooperation alliance with background and theoretical analysis. In the second section, we conduct in-depth analysis on the traditional outstanding engineer education training plan. In the third part, we propose the novel and revised plan for the education pattern. Finally, we summarize the work and give the prospect.

\section{The Proposed Methodology}

The Primary Concepts of the University-Enterprise Cooperation Alliance. Across the countries of the university-enterprise cooperation development process can be found, the enterprise technology innovation as main body, should play a role of main body status in university-enterprise cooperation, but because our country university-enterprise cooperation innovation has not entered the mature stage, combined with system reform is not perfect from objectively caused the main body status of enterprises in university-enterprise cooperation innovation. In innovation of enterprises and colleges and universities cooperation purpose, the method and way of participation differences, technology innovation as the product of cooperation at the same time, there is innovation, risk-taking and other issues of profit distribution to makes the university-enterprise cooperation to present different effects. Based on this, this article through the empirical analysis, from the perspective of enterprise analysis factors that influence the effect of university-enterprise cooperation thus to promote the effect of the cooperation between colleges promote the enterprise technology innovation to provide better service strategy and way. University-enterprise cooperation in the running schools is kind of based on market and social needs as the goal orientation of the common ways of fostering talents and the school and 
enterprise is the main body of talent training which also is the key to realize co-prosperity benefit. In the following parts, we analyze the characteristics of the pattern [5].

$>$ The university-enterprise cooperation complementarity is embodied in two aspects, one is the complementary resources type the other is complementary technology knowledge. Resources focus on the teaching and teaching fields and facilities for students. Enterprise as a productive place can provide the production practice of the premises and facilities or jointly with college practice base construction. Through the cooperation between colleges and technical staff and faculty of complementary and integration of knowledge to better develop the students' ability of practice and innovation to eventually improve the quality of talent.

$>$ University-enterprise cooperation to obtain the high quality talent in the tide of economic globalization is the necessary way which is a kind of training mode of cooperation benefits on both sides. In the fierce competition environment, enterprise development and the status quo of this industry have a deeper understanding, so for the future of enterprise talent requirement types and the quality is also very clear. Through the general cooperation of the colleges and universities can get more money and resources to promote the students' practical experience. It can also increase social communication, improve the influence. In addition, the improvement of personnel quality also helps to improve the reputation of colleges and universities in order to win more cooperation opportunities and material support.

$>$ Cooperation through the establishment of the cooperation contract, form a long-term, stable relation of cooperation is to obtain high quality talents, the necessary condition to save costs. The establishment of good relations of cooperation to promote the cooperation between the two sides will, thus improve the effect of cooperation [6].

According to the general definition, operation mechanism refers to the regular exercise in human society, the various influence factors of the movement of the structure, function and their relations. As well as the influence of these factors and function process and function principle and operation mode. Effect of the operation mechanism of the university-enterprise cooperation affect is to coordinate the relationship between colleges of various subjective and objective factors and it is government policies and regulations, system of education development, the influence of the social economic and cultural aspects and through the university-enterprise cooperation mode. In the following figure 2, we show the features and main characteristics of the university-enterprise cooperation alliance.

Sustainability Driven Entrepreneurship, Policies and Innovation Joint Master Programme

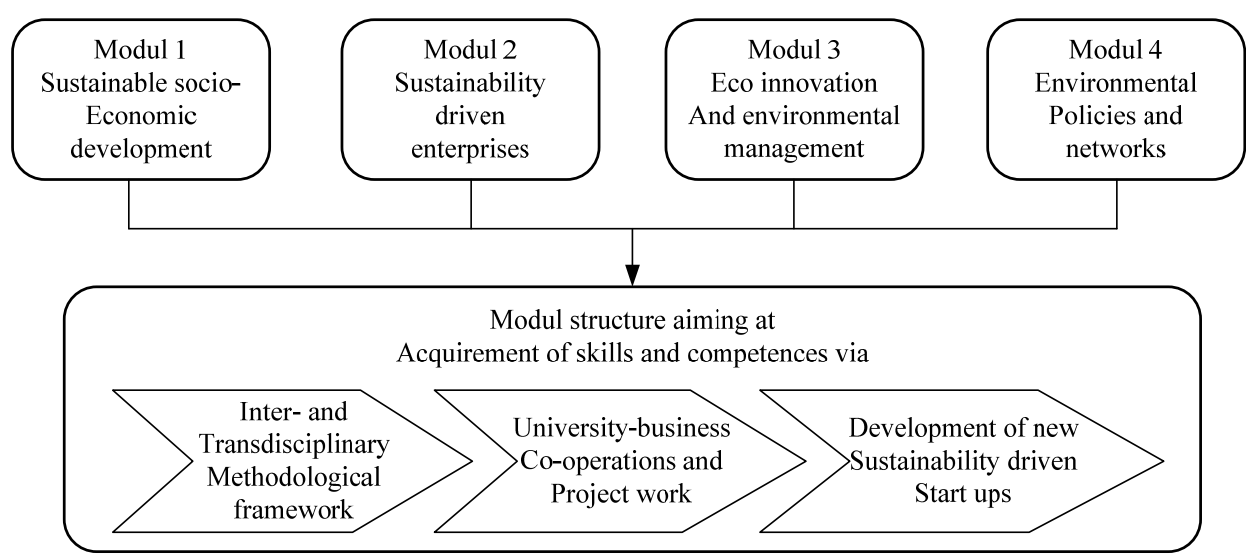

Figure 2. The Main Characteristics of the University-Enterprise Cooperation Alliance

The Traditional Outstanding Engineer Education. Engineering training center of teaching as an important implement campus practice base and engineering teaching base, not only to complete the basic practice teaching tasks should be based on this, the practice of cultivating "excellence initiative" related professional student ability to innovate. To become engineers should have the basic skills and comprehensive quality cultivation and training. Engineering education is for the national economic construction and the social development in the main channel to provide the engineering and technical personnel, engineering and technology in dealing with human needs, and promote 
social development will play a more and more important. High and the new technology such as information, biology, new materials of science for the mushroom action speed development, the globalization of economy and market trends and the increasingly fierce competition of the international scope with the cultivation of engineers put forward new and higher broader requirements. To strengthen the training of engineering practice, cultivate and improve operation of the engineering and technical personnel practical ability and innovative thinking ability of engineering education reform is imperative.

The current traditional training mode is suffering from the following drawbacks and challenges. (1) For a long time, the traditional teaching concept encourages culture of "exam-oriented education", prompting students to pour all his energies in graduation examination, result in institutions of higher learning will achieve higher education as the highest goal of education and inhibits learning autonomy and initiative which imprisoned the personality development of students, hinders the development of students' creative thinking and innovation consciousness. A lot of formal training and the students have opportunity to enter the enterprise practice but time is shorter that hands-on practice into rem, the experience becomes a perceptual knowledge. (2) Lack of personalized training mode. University characteristics include the characteristics of school-running characteristics is refers to the institutions of higher learning in the long history on the basis of the formation of the unique style of teaching and unique educational philosophy and culture on campus, characteristic of talents cultivation, scientific research, etc. Characteristics of mystique, stability and expansibility which are closely linked with the high quality innovative talents cultivation is a lot of colleges and universities in our country in the aspect of talent cultivation lack innovative consciousness and innovative spirit [7].

The Novel and Revised Plan for the Education Pattern. Excellent engineer training emphasis on comprehensive quality and also emphasizes the engineering practice ability. Therefore, outstanding engineers training quality standards of both quantitative and qualitative. Although the training quality during the period of school can be periodic inspection and evaluation through teaching process, but on the jobs after graduation can truly reflect the training quality of behavior. So, outstanding engineers training quality evaluation has certain hysteresis and tardy. If the enterprise timely feedback can more effectively to adjust and control the teaching process based on the understanding of the specificity of training quality, establish the teaching quality monitoring process control system.

Undergraduate teaching reform for the engineering research is a theoretical value and the realistic significance to research topic. In theory, higher education can help enrich the teaching theory and the teaching reform of higher education theory system more perfect. In practice, it also helps to promote university teaching reform effectively and provide help for the teaching reform practice process. The theoretical basis is demonstrated as the follows. (1) Engineering undergraduate specialty construction and adaptability of teaching reform, social demand is the emphasis and difficulty in higher education reform. (2) This study engineering undergraduate teaching reform from the perspective of feasibility study engineering undergraduate colleges and teaching reform in order to have comprehensive understanding, system, rational for the future teaching reform further forward to the depth and height to lay the foundation. (3) Engineering undergraduate specialty construction adaptability research of teaching reform and the social demand, help to enrich higher education research, development and perfect the reform of higher education theory. Excellence engineers require both possess solid deep knowledge accomplishment at the same time to be able to use more profound professional knowledge to take on social problems. From cultivating "excellence engineers" the goal of engineering practice ability and excellent engineer training must change the subsidiary position of practice teaching for a long time, to strengthen training students' comprehensive application and ability to solve practical problems as the center and the construction of engineering practice ability training platform.

$>$ Practice base and production base of off-campus practice teaching platform. Production study research cooperation way, such as strengthening the construction of off-campus practice base, build campus practice teaching environment. Increase in number of practice base to realize epitaxy expand at the same time, strengthen the connotation of the practice base construction, 
improve the practical teaching effect. Off-campus practice teaching environment construction is to realize the cultivation of outstanding engineers out of school, combined with production practice as an important guarantee of training students' ability to solve practical problems.

$>$ Combined guide students graduation design. To cultivate students' comprehensive ability to solve practical problems, in view of the graduation design, often can't contact engineering, the limitations of actual production, to encourage teachers and industry production management the first line of joint engineering technical personnel to guide the students' graduation design. Students in the process of complete the graduation design can always consult the enterprise have experienced technical staff learned a lot of class can't go to school, school teachers can teach some practical experience [8].

$>$ Experiments and practical pay equal attention to the campus practice teaching platform. Organize the teachers by combining specialized laboratory construction and designed with the mainstream of choose and buy production equipment, electrical and mechanical equipment of similar structures, operating system simulation of practical engineering practice. According to the production operation procedures for simulation operation training, the production process. The engineering training center creates favorable conditions for basic engineering simulation teaching and training which provide students with numerical control equipment operation, maintenance, repair and establishment of complex molding process.

Participate in colleges and universities on the basis of careful analysis of the above two aspects diversity, follow the principle of the engineering talents cultivation orientation, as a service oriented principle, level principle, the principle of their own advantages and future demand principle can accurately find the "excellence initiative" talent cultivation orientation of our school and ultimately reflected in school outstanding engineers training objectives to lay foundation for the establishment of professional training scheme. The figure three demonstrates the concept.

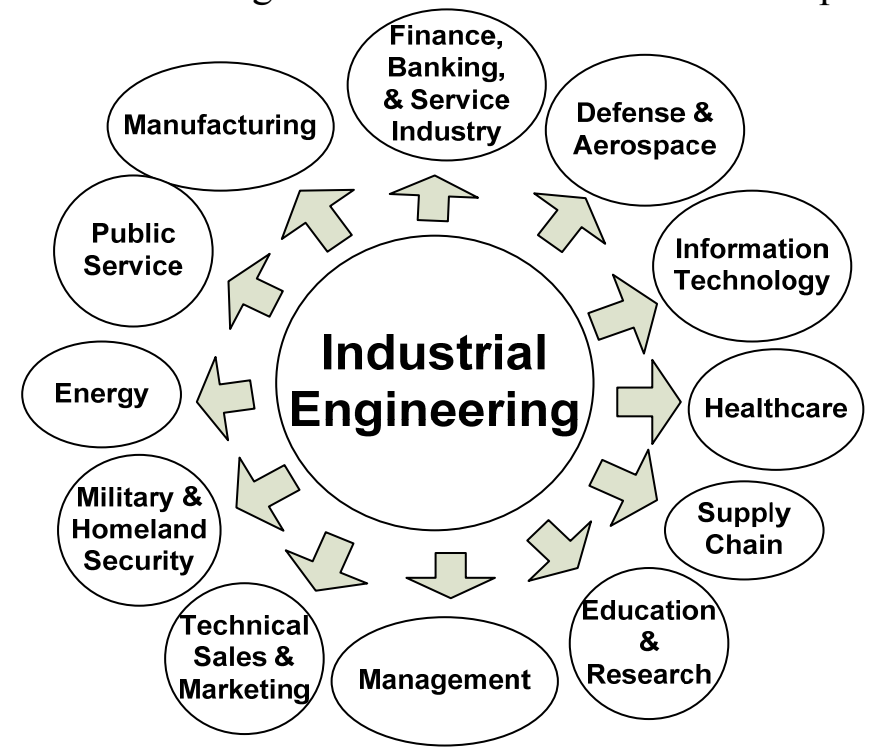

Figure 3. The Characteristics and Syllabus of the Modern Revised Plan for the Education Pattern

\section{Conclusion}

In this paper, we conduct research on the IT outstanding engineer education training plan based on university-enterprise cooperation alliance. School and enterprise cooperation, we could summarize as: the high starting point, zero distance, deep, double strategy. That is to say, university-enterprise cooperation to stand tall in the train of thought, the farther, starting from the shared vision of school and enterprise development and takes the hot issues of mutual concern to science and the education encouraging city level of communication and as whole. Operate to low center of gravity, operational, starting from the direct demand of enterprise with authorized in direct contact with the work level and work directly with the enterprise integrated schools. In the future, we will apply our proposed novel methodology into the applications to test the effectiveness. 


\section{Acknowledgements}

This research was financially supported by the 2015 Research Project of Higher Education Reform in Shaanxi (15BY126) and the 2015 Teaching Reform Research Planning Project of Xijing University (JGGH1511).

\section{References}

[1] Ji-gang, C. A. I. "Adjustment of Educational Assessment of EFL at Tertiary Level against the Background of Internationalization of Higher Education [J]." Computer-Assisted Foreign Language Education 1 (2013): 003.

[2] Gibbs, Norman E., and Richard E. Fairley, eds. Software engineering education: the educational needs of the software community. Springer Science \& Business Media, 2012.

[3] Blue, Ethan, Michael Levine, and Dean Nieusma. "Engineering and war: militarism, ethics, institutions, alternatives." Synthesis lectures on engineers, technology, and society 7, no. 3 (2013): $1-121$.

[4] Cha, Chaenyung, Su Ryon Shin, Nasim Annabi, Mehmet R. Dokmeci, and Ali Khademhosseini. "Carbon-based nanomaterials: multifunctional materials for biomedical engineering." ACS nano 7, no. 4 (2013): 2891-2897.

[5] Chalmers, Denise. "Progress and challenges to the recognition and reward of the scholarship of teaching in higher education." Higher Education Research \& Development 30, no. 1 (2011): 25-38.

[6] Csikszentmihalyi, Mihaly, and Rustin Wolfe. "New conceptions and research approaches to creativity: Implications of a systems perspective for creativity in education." In The Systems Model of Creativity, pp. 161-184. Springer Netherlands, 2014.

[7] Huang, Huan, Pengwan Chen, Xuetong Zhang, Yun Lu, and Wanchu Zhan. "Edge - to - edge assembled graphene oxide aerogels with outstanding mechanical performance and superhigh chemical activity." Small 9, no. 8 (2013): 1397-1404.

[8] Shi, Shan, Chengjun Xu, Cheng Yang, Yanyi Chen, Juanjuan Liu, and Feiyu Kang. "Flexible asymmetric supercapacitors based on ultrathin two-dimensional nanosheets with outstanding electrochemical performance and aesthetic property." Scientific reports 3 (2013). 